\title{
Comparison of Photovoltaic panel's standard and simplified models
}

\author{
Masud Rana Rashel ${ }^{1 *}$, Andre Albino ${ }^{1}$, Angela Veiga ${ }^{1}$, \\ Md. Tofael Ahmed ${ }^{1}$, Mouhaydine Tlemcani ${ }^{1}$ \\ 1: Department of Physics, University of Évora \\ e-mail:masudranarashel@gmail.com
}

\author{
Teresa C. F. Goncalves ${ }^{2}$ \\ 2: Department of Informatics, \\ University of Évora
}

\begin{abstract}
Shockley diode equation is basic for single diode model equation, which is overly used for characterizing the photovoltaic cell output and behavior. In the standard equation, it includes series resistance $\left(R_{s}\right)$ and shunt resistance $\left(\mathrm{R}_{\mathrm{sh}}\right)$ with different types of parameters. Maximum simulation and modeling work done previously, related to single diode photovoltaic cell used this equation. However, there is another form of the standard equation which has not included Series Resistance $\left(R_{s}\right)$ and Shunt Resistance $\left(R_{\text {sh }}\right)$ yet, as the Shunt Resistance is much bigger than the load resistance and the load resistance is much bigger than the Series Resistance For this phenomena, very small power loss occurs within a photovoltaic cell. This research focuses on the comparison of two forms of basic Shockley diode equation. This analysis describes a deep understanding of the photovoltaic cell, as well as gives understanding about Series Resistance $\left(\mathrm{R}_{\mathrm{s}}\right)$ and Shunt Resistance $\left(\mathrm{R}_{\mathrm{sh}}\right.$ ) behavior in the Photovoltaic cell. For making estimation of a real time photovoltaic system, faster calculation is needed. The equation without Series Resistance and Shunt Resistance is appropriate for the real time environment. Error function for both Series resistance $\left(R_{s}\right)$ and Shunt resistances $\left(R_{\text {sh }}\right)$ have been analyzed which shows that the total system is not affected by this two parameters' behavior.
\end{abstract}

Keywords-Photovoltaic cell; Series Resistance; Shunt Resistance; Error Function;

\section{INTRODUCTION}

The world is running out of energy sources and the scientists all over the world are working on establishing new sources of energy. Renewable energy is one of the important sources of new kind of energy which is good for environment and the sources of these technologies are available around us. Among the entire sources, the sun is the most available source of energy and scientists are working to use the energy of sun to get workable energy. Among different types of solar energy producing system, photovoltaic cell is important and it is growing exponentially. Different kinds of photovoltaic cells have been invented and researchers are trying to improve their performance.
Photovoltaic cell is the device which converts solar energy to electrical energy. There is no harmful wastage from this device. This device is working on the basic physical phenomenon based on photo effect. When light with enough frequency strikes on the semiconductor surface, it ejects electron and this electron is the cause of electrical flow. The working principle is very simple for photovoltaic cell. Main problem of photovoltaic cell is the performance and cost. Scientists are working to improve the performance and reduce cost.

There are different kinds of photovoltaic cell in the market. Scientists are working to improve the performance of photovoltaic cell. To improve the performance, it is very important to understand the mechanism of photovoltaic cell and their internal behavior. Single diode photovoltaic cell diagram is one of the basic diagrams for understanding photovoltaic behavior internally $[1,4]$. From this figure 1 , the internal behavior of photovoltaic cell is presented by this single diode photovoltaic model.

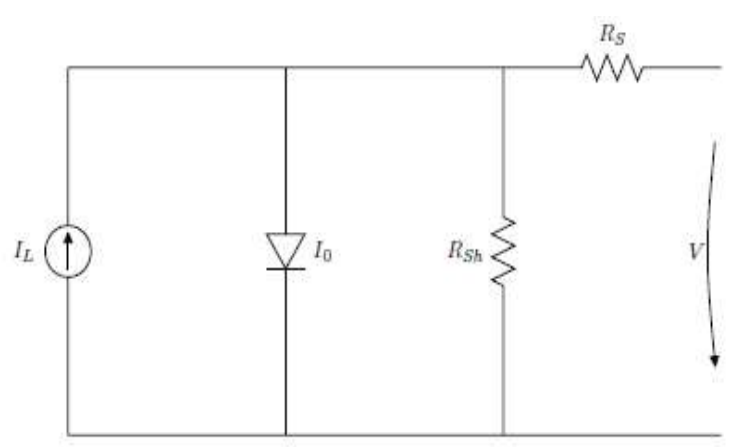

Figure 1: Single diode photovoltaic cell

In this figure the total photovoltaic cell is represented by a single diode model which shows current source $I_{L}$, a photodiode $I_{0}$, a Series resistance $R_{s}$, a Parallel Shunt resistance $R_{s h}$ and load $\mathrm{V}$. This is the ideal setup for single diode photovoltaic cell [3-7]. This configuration is presented by equation 1 which is used for photovoltaic cell analysis. 


$$
I=I_{L}-I_{0}\left[\exp \left(\frac{V+I R_{z}}{n k T}\right)-1\right]-\frac{V+I R_{z}}{R_{s h}}
$$

In this equation, the figure 1 is fully described. Here, $\mathrm{n}$ is ideal factor of photovoltaic cell, $K$ stands for Boltzmann constant, $T$ is the temperature, $I$ for output current from the total system. From the figure 1 and in equation $1, R_{s}$ and $R_{s h}$ are used for getting the total current output of the photovoltaic cell [8-12]. In Next section it will be described that it is possible to get nearly the same output without taking Rs and $R_{\text {sh }}$ into account when calculating the current output.

\section{THEORY AND METHOD}

Two equations have almost the same types of parameters as one is the simple form of another. The shunt resistance is bigger enough than the series resistance and load resistance. Load resistance is also bigger enough than series resistance $[1,5]$, that's why it can be possible to ignore the series and shunt resistance in the basic Shockley diode equation ${ }^{1}$ and use simplified equation of the standard equation. The basic photovoltaic cell parameters are shown in the figure 1.

Standard photovoltaic cell equation is derived from the Shockley diode equation and it is represented by the equation 1. Equation 1 fully describes the figure 1 which represents the photovoltaic cell. In practical photovoltaic cell Shunt resistance is much higher than load resistance. On the other hand, Series resistance is much smaller than load resistance. When these things are taken into account the loss in the cell become very less and it is possible to ignore Series and Shunt resistance. Without Series and Shunt resistance the equation 1 becomes equation 2 .

$$
I=I_{L}-I_{0}\left[\exp \left(\frac{\theta V}{n k T}\right)-1\right]
$$

Equation 2 is the simplified form of equation 1. Following are the steps shows how the equation 1 becomes equation 2 after ignoring some terms.

$$
\begin{aligned}
& \exp \frac{e(V+I R s)}{n K T}-1 \\
& \exp \frac{e V}{n K T}-1
\end{aligned}
$$

(3) Become

(4) When $R_{s}$ is very small.

at the last part of equation 1 there is $\mathrm{R}_{\mathrm{s}}$ and $\mathrm{R}_{\mathrm{sh}}$. The equation has been simplified and the last part has been ignored for building equation 2 .
When these terms become zero or very small, it is possible to ignore them. $R_{s}$ is very small and $R_{s h}$ is very large, in these condition equation 1 becomes equation 2 .

To test the sensitivity of $R_{s}$ and $R_{s h}$ to the total output, an error function is used.

$E(J)=\frac{1}{n}\left(\sum_{i=1}^{\mathrm{n}}\left(I_{n d i}-I_{\mathrm{err}}\right)^{2}\right)^{1 / 2}$

Varying the $R_{s}$ and $R_{s h}$ value one by one the sensitivity to the total system is found.

Equation 6 is used for sensitivity analysis, here $R_{s}$ value is changed around the standard value and it shows no effect on the total system. Because it doesn't make any variation when the value is changed. There is no significant change in the curve structure.

When $R_{s h}$ value is changed from its standard value it shows little effect on the output. The effect is very less on the total system. In the figure 2 , the effect on the total system is shown. The curve is not that much vary in wide range of the input.

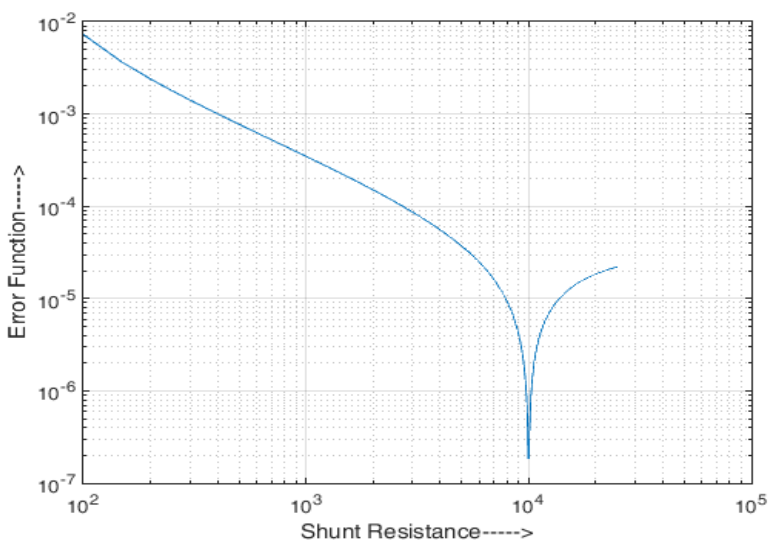

Figure 2: Error function Vs Shunt Resistance

From the graph, it results that Series and Shunt resistance can be ignored and equation 2 can be used for faster processing of simulation.

\section{RESULTS}

After getting the equation 2 from the equation 1 ignoring Series resistance and Shunt Resistance, it is important to analyze the output from both equations. Using both equation 1 
and 2 , the I-V and P-V graph are drawn to see their behavior.

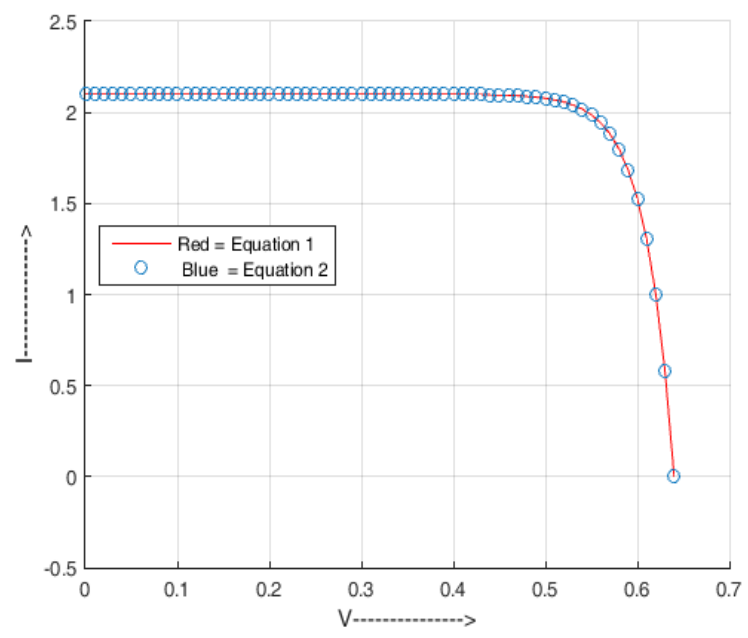

Figure 3: I-V curve using equation 1 and 2

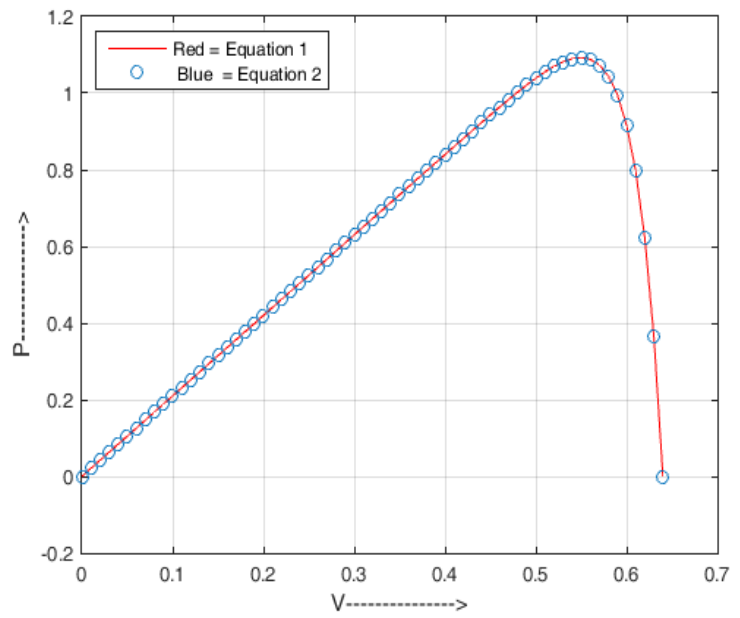

Figure 4: $\mathrm{P}-\mathrm{V}$ curve using both equation 1 and 2

Using the both equation the I-V and P-V curve have been drawn. (see Figure. 2 and Figure. 3). The curve shows almost same behavior for both equations. In MATLAB the time to calculate the first equation takes more than calculating the value for the second equation. From the error function, the series resistance shows no sensitivity to the photovoltaic cell. Shunt resistance shows sensitivity to the photovoltaic output but the sensitivity is not much significant. It is possible to use the second equation that does not contain the series resistance and shunt resistances value. Without these two parameters the $\mathrm{I}-\mathrm{V}$ and $\mathrm{P}-\mathrm{V}$ curve gives the ideal behavior in simulation along with the standard value. Figure 5, shows the difference between two outputs of the equations respectively. From the graph, it is clear that two equations have very low difference and it is possible to use the second equation for faster computation in real time system.

This work is done under the funded of Erasmus Mundus Fusion Project.

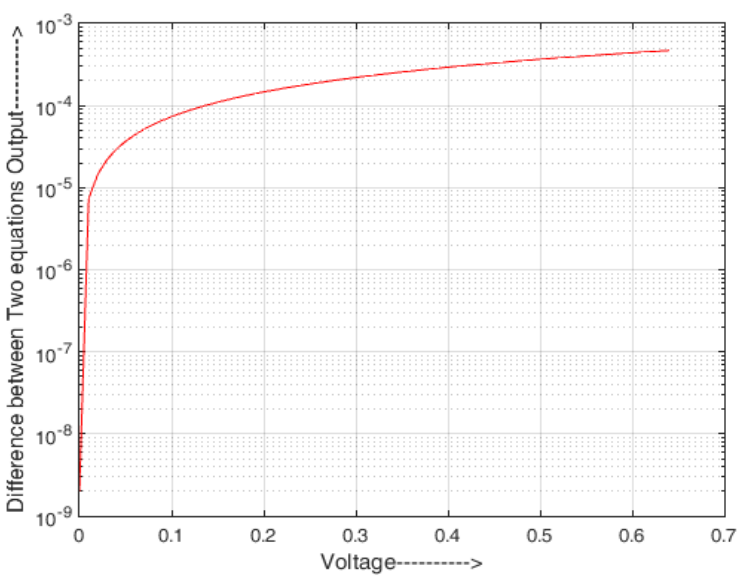

Figure 5: voltage and two equations current output difference

It is viewed that the difference between the standard and simplified model is not that much.

\section{CONCLUSTION}

The difference between standard and simplified model is not that much. For faster computation and real time simulation, the simplified model can be used to get the result faster. But in sensitive calculation the standard model should be used because of getting accurate result from the system.

For using the second equation in real time system, it needs little more investigation. Like using equation 2 in the real field and identifying the difference between equations. The work is going on for more verification.

\section{ACKNOWLEDGEMENT}

Thanks to Erasmus Mundus Fusion project for funding the scholarship and ICT of University of Evora to give opportunity to do the research.

\section{REFERENCES}

[1] Soteris A. Kalogirou, Solar Eneroy Engineering, Ed., 2nd Edition ed. AMSTERDAM • BOSTON $\bullet$ HEIDELBERG $\bullet$ LONDON NEW YORK $\cdot$ OXFORD • PARIS • SAN DIEGO SAN FRANCISCO • SINGAPORE - SYDNEY • TOKYO: Elsevier.

[2] Chatterjee, A. Keyhani, and D. Kapoor, "Identification of Photovoltaic source models," IEEE Transactions on Energy Conversion, vol. 26, no. 3, pp. 883-889, Sep. 2011.

[3] Dominique Bonkoungou, Zacharie Koalaga, and Donatien Njomo," Modelling and Simulation of photovoltaic module considering single diode equivalent circuit model in MATLAB," International Journal of Emerging Technology and Advanced Engineering, vol. 3, no. 3, pp. 593-502, Mar. 2013.

[4] F. Ghani, G. Rosengarten, M. Duke, and J. K. Carson, "The numerical calculation of single-diode solar-cell modelling parameters," Renewable Energy, vol. 72 (2014), pp. 105-112, Jul. 2014.

[5] D. Sera, R. Teodorescu, and P. Rodriguez, "PV panel model based on datasheet values," pp. 2392-2396, Jun. 2007. 
[6] J. Cubas, S. Pindado, and A. Farrahi, "New method for analytical photovoltaic parameter extraction," pp. 873-877.

[7] Jitendra Bikaneria, Surya Prakash Joshi, and A. R. Joshi, "Modeling and Simulation of PV Cell using One-diode model," International Journal of Scientific and Research Publications, vol. 3, no. 10, Oct. 2013.

[8] N. Aoun, R. Chenni, B. Nahman, K. Bouchouicha, and S. R. Publishing, "Evaluation and validation of equivalent Five-Parameter model performance for Photovoltaic panels using only reference data," Energy and Power Engineering, vol. 06, p. 235, Sep. 2014.

[9] Ahmed A. EL TAYYAN, "A simple method to extract the parameters of the single-diode model of a PV system," Turkish Journal of Physics, vol. 37, pp. 121-131, Mar. 2013.
[10] R. Chenni, M. Makhlouf, T. Kerbache, and A. Bouzid, "A detailed modeling method for photovoltaic cells," Energy, vol. 32, no. 9, pp. 1724-1730, 2007.

[11] S. Lineykin, M. Averbukh, and A. Kuperman, "Five-parameter model of photovoltaic cell based on STC data and dimensionless," 2012 IEEE 27 th Convention of Electrical and Electronics Engineers in Israel, pp. $1-5$.

[12] Ahmed A. El Tayyan, "PV system behavior based on datasheet," Journal of Electron Devices, vol. 9, pp. 335-341, 2011. 